\title{
A Comparison of Catalytic Properties of Glutamate Dehydrogenase from Liver and Muscle between Amphibious Periophthalmus cantonensis and Water-breathing Gobid Fishes Tridentiger obscurus obscurus
}

\author{
Katsuya IwaTA and Izuru KaKuTA* \\ (Accepted April 9, 1983)
}

\begin{abstract}
The catalytic properties of glutamate dehydrogenase of the liver and muscle from an amphibious gobid fish, Periophthalmus cantonensis were compared with those of the enzymes from a water-breathing gobid fish, Tridentiger obscurus obscurus.

The enzyme activities in the liver and muscle of $P$. cantonensis increased to a greater degree with rising ambient salinities than those observed with $T$. obscurus obscurus, when they were acclimated in different salinities for 7 days.

The apparent $\mathrm{Km}$ for $\mathrm{NH}_{4}^{+}$of the muscle enzyme from $P$. cantonensis was about half as much as that of the enzyme from $T$. obscurus obscurus, while those values of the liver enzymes from both species were essentially similar. No species-difference was observed in other kinetic constants of the enzymes from the two gobid fishes including the $K m^{\prime}$ 's for $\alpha$-ketoglutarate and NADH, the $K a$ 's for ADP and leucine and the $K i$ 's for GTP (in the absence of ADP), NAD ${ }^{+}$ and glutamate.

The effect of ADP on the liver enzyme from $P$. cantonensis was stronger than that of the enzyme from $T$. obscurus obscurus, while the effects of ADP on the muscle enzymes from both the species were similar. The effects of ADP on GTP-inhibited enzymes from $P$. cantonensis were much greater than the corresponding effects on the enzymes from $T$. obscurus obscurus. These results suggest that the enzymes from $P$. cantonensis were more tightly regulated by ADP-GTP interaction than the enzymes from $T$. obscurus obscurus.
\end{abstract}

The mudskipper, Periophthalmus cantonensis spends the greatest part of its life on mudflat out of water. Most fish excrete ammonia as the end product of protein metabolism. It has been reported that the level of ammonia excretion by the mudskipper is very low during the period out of water. ${ }^{2-3}$ ) Since ammonia is a highly toxic compound, it must be removed, either to the exterior or by conversion into less toxic compounds. It is well known that the lung-fish" as well as semi-terrestrial amphibians ${ }^{\circ}$ converts ammonia into urea during their terrestrail lives. On the other hand, in the previous work, ${ }^{3}$ we found that the mudskipper kept either out of water or in a hyper-osmotic medium accumulated a great amount of free amino acids, especially non-essential ones as well as ammonia in its tissue, whereas urea increased to a lesser extent. Under these circumstances, the activities of glutamate dehydrogenase (EC-1.4.1.2.) from liver and muscle markedly increased. In the mudskipper, therefore, glutamate dehydrogenase catalyzing reductive amination of $\alpha$-ketomglutarate seems to play a central role in removing ammonia from the tissue while the fish was subjected to conditions of water-shortage.

In the present study, we examined catalytic properties of glutamate dehydrogenase from liver and muscle of $\boldsymbol{P}$. cantonensis kept either out of water or in hyper-osmotic media. In addition, the catalytic properties of $P$. cantonensis were compared with those of a water-breathing gobid fish, Tridentiger obscurus obscurus which survives well either in fresh water or in $120 \%$ sea water. The present study was undertaken for determining what differences were associated with the transition to an amphibious life-style.

\section{Materials and Methods}

$P$. cantonensis and $T$. obscurus obscurus were collected at the estuary of Tanabe Bay and Susami

* Faculty of education, Wakayama University, Wakayama 640, Japan（岩田勝堿 ·角田 出：和歌山大学 教育学部生物学教室). 
River in Wakayama Prefecture respectively. They were kept in $20 \%$ sea water (S.W.) for a month before use, Throughout the rearing periods, chironomid larvae were daily supplied as a food. The mudskipper was then acclimated in 20,50 and $80 \%$ S.W. for 7 days, and kept out of water for 3 days as described previously. ${ }^{3)}$ T. obscurus obscurus was directly transferred to fresh water, $20,50,80$ and $120 \%$ S.W., and acclimated in each medium for 7 days. During the period of acclimation, both species were starved and held at a temperature of $20^{\circ} \mathrm{C} \pm 1$.

Liver and muscle tissues from both species were dissected out, blotted, and homogenized in 5 vol. of $0.25 \mathrm{M}$ sucrose with $0.1 \mathrm{~mm}$ EDTA in $3 \mathrm{~mm}$ Tris- $\mathrm{HCl}$ buffer $(\mathrm{pH}$ 7.4). No purification of the enzyme was attempted, and the crude mitochondrial fraction was used for the enzyme assay. The procedures for the preparation of mitochondrial fraction and for the enzyme assay were the same as previously described. ${ }^{3)}$ For purposes of comparison, the enzyme activities in gill and skin from both species were also examined. The enzyme activity was expressed as specific activityunit ( $\mu \mathrm{mol} \mathrm{NADH} / \mathrm{min}$./mg protein).

The apparent $K m$ values for substrates were determined by means of Lineweaver-Burk plots using at least seven different concentrations of substrate. The apparent $K a$ and $K i$ values were estimated from Lineweaver-Burk plots and Dixon plots respectively. Kinentic constants for allosteric effectors were derived from Hill plots. Standard deviations were calculated for enzyme activities and for kinetic constants. Results were compared using Student's $t$-test.

\section{Results}

\section{Effect of $p H$}

The $\mathrm{pH}$ dependence of the liver enzyme from $P$. cantonensis kept out of water is shown in Fig. 1. The pH optimum in the direction of reductive amination was about 7.5 , in the reverse direction it was 8.5-9.0.

The activity of the liver enzyme as assayed in the direction of oxidative deamination was very low, which was about $10 \%$ of that in the reductive amination in the presence of ADP. In common with glutamate dehydrogenase from other fish sources, ${ }^{6-10)}$ the liver enzyme showed very low activity with NADPH as coenzyme. The actibity with $\mathrm{NADP}^{+}$could not be detected in the present assay condition.

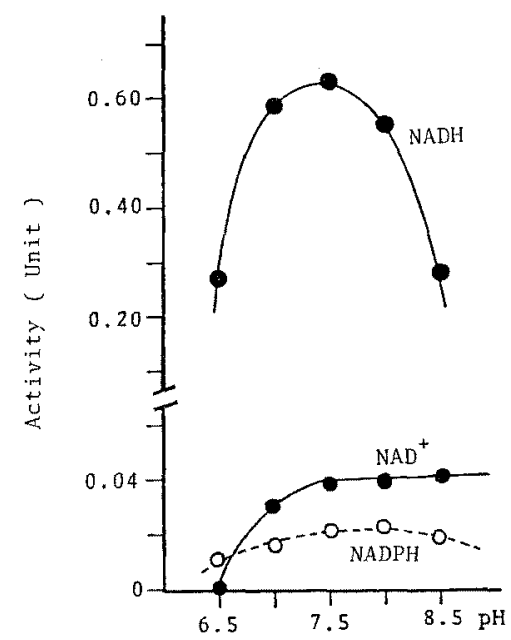

Fig. 1. The pH profiles of glutamate dehydrogenase from the liver of $P$. cantonensis. Enzyme was assayed in both the directions of the reductive amination (NADH and NADPH) and of the oxidative deamination $\left(\mathrm{NAD}^{+}\right)$under the optimal conditions (in the presence of $0.15 \mathrm{~mm}$ ADP).

The enzyme from the muscle of $P$. cantonensis as well as the enzymes from the liver and muscle of $T$. obscurus obscurus was found to be similar in these respects.

\section{Enzyme Activities}

The activities of the enzymes from liver, muscle, skin and gill from both species as assayed in the reductive amination using the optimal conditions are shown in Fig. 2. Of the tissues examined, the liver of both species had the highest enzyme activities, and the muscles showed the lowest. In each tissue from both species, the enzyme activity increased with rising ambient salinities. The activity in each tissue from $T$. obscurus obscurus increased a lesser degree with rising salinity as compared with that from $P$. cantonensis, although the activity in each tissue, especially in the liver from $T$. obscurus obscurus kept in $20 \%$ S.W. (Control) was much higher than that of $P$. cantonensis. The activity in each tissue from $T$. obscurus obscurus kept in $120 \%$ S.W. was $1.3-$ to 1.8 -fold of that in $20 \% \mathrm{~S} . \mathrm{W}$., while the activity of $P$. cantonensis kept in $80 \%$ S.W. increased 2 to 3 -fold of that in $20 \%$ S.W. In $P$. cantonensis kept out of water, the enzyme activity in each tissue increased 3- to 4-fold of that in $20 \% \mathrm{~S}$.W. 

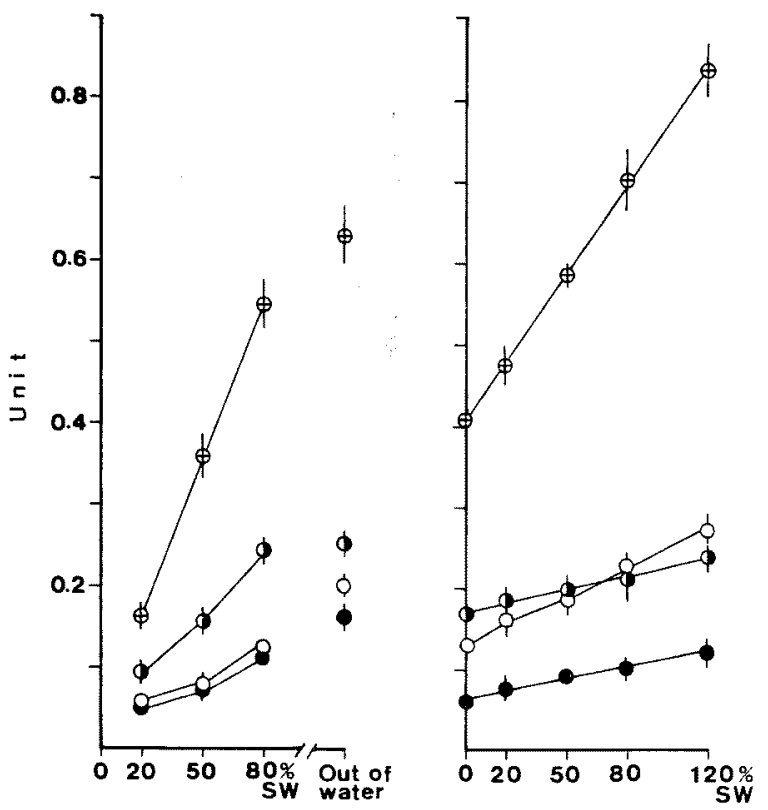

Fig. 2. The activities of glutamate dehydrogenase from various tissues of $P$. cantonensis (Left) and of $T$. obscurus obscurus (Right) kept either in different salinities or out of water. Enzymes were assayed in the direction of reductive amination under the optimal conditions (in the presence of $0.15 \mathrm{~mm}$ ADP). The bar on each point indicates the standard deviation. Liver

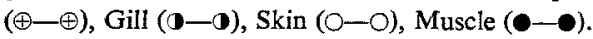

Table 1. Apparent $K m$ values of glutamate dehydrogenase from liver and muscle of $P$. cantonensis and of T. obscurus obscurus

\begin{tabular}{lccccc}
\hline \multirow{2}{*}{ Kinetic constants, $\mathrm{mM}$} & \multicolumn{2}{c}{ P. cantonensis } & & \multicolumn{2}{c}{ T. obscurus obscurus } \\
\cline { 2 - 3 } \cline { 5 - 6 } & Liver & Muscle & & Liver & Muscle \\
\hline$K m$ Ammonia (-ADP) & $86.24 \pm 6.59(16)$ & $59.73 \pm 5.50(16)$ & & $116.04 \pm 19.09(6)$ & $100.00 \pm 25.49(6)$ \\
$K m$ Ammonia (+ADP) & $66.08 \pm 7.81(8)$ & $40.05 \pm 6.57(8)$ & & $85.80 \pm 10.73(6)$ & $83.72 \pm 10.97(6)$ \\
$K m \alpha$-ketoglutarate (-ADP) & $0.64 \pm 0.10(3)$ & $0.56 \pm 0.02(3)$ & & $0.63 \pm 0.01(3)$ & $0.85 \pm 0.02(3)$ \\
$K m \alpha$-ketoglutarate (+ADP) & $1.16 \pm 0.21(3)$ & $1.05 \pm 0.10(3)$ & & $1.25 \pm 0.04(3)$ & $1.10 \pm 0.06(3)$ \\
$K m$ NADH (-ADP) & $0.018 \pm 0.003(3)$ & $0.021 \pm 0.006(3)$ & & $0.017 \pm 0.002(3)$ & $0.015 \pm 0.001(3)$ \\
$K m$ NADH (+ADP) & $0.032 \pm 0.004(3)$ & $0.031 \pm 0.004(3)$ & & $0.046 \pm 0.002(3)$ & $0.038 \pm 0.001(3)$ \\
\hline \multicolumn{3}{c}{ When added, ADP concentration was 0.15 mM. Figures in parentheses indicate the number of sample } & (Mean \pm S.D.)
\end{tabular}

\section{Kinentic Constants}

The apparent $K m$ values for $\mathrm{NH}_{4}^{+}, \alpha$-ketoglutarate and NADH are listed in Table 1. The enzymes from both species showed kinetics of simple Michaelis type for these substrates. The apparent $\mathrm{Km}$ values for $\mathrm{NH}_{4}^{+}$of the liver enzyme from $P$. cantonensis in the absence and the presence of ADP ( $0.15 \mathrm{mM})$ were higher than those values observed with the muscle enzyme $(\mathrm{p}<$ 0.001). The present $K m$ values for $\mathrm{NH}_{4}^{+}$of the enzymes from $P$. cantonensis were slightly different from those of the previous report ${ }^{\mathrm{g})}$ which were estimated using insufficient number of samples.

There was no difference between the $K \mathrm{~m}^{\prime} \mathrm{s}$ for $\mathrm{NH}_{4}^{+}$of the liver enzyme and those of the muscle enzyme from $T$. obscurus obscurus. It should be noted that the $\mathrm{Km}^{\prime}$ 's for $\mathrm{NH}_{4}^{+}$of the muscle enzyme from $T$. obscurus obscurus in either the absence or the presence of ADP were about twice as much as those observed with the enzyme from $P$. cantonensis. The Km's for $\mathrm{NH}_{4}^{+}$of the enzymes from gill and skin of both species were similar to those of the liver enzyme either from $P$. cantonensis or from $T$. obscurus obscurus. The enzymes from both species had essentially similar $K m$ 
values for $\alpha$-ketoglutarate in either the absence or the presence of ADP. No difference was also found in the apparent $K m$ values for NADH of the enzymes from the two gobid fishes.

The apparent $K m$ values of the liver and muscle enzymes from both species for substrates as mentioned above were not different among the fishes adapted to different conditions.

\section{Activitors and Inhibitors}

The effects of activators and inhibitors on the enzymes are shown in Table 2. Of the activators examined, ADP was the most effective, and the liver enzyme from $P$. cantonensis was activated to a greater degree by ADP than that from $T$. obscurus obscurus, while the effects of ADP on the muscle enzymes from both species were similar. The curve relating the enzyme activity to ADP concentration was sigmoidal for the liver and muscle enzymes from both species. This curve suggests an allosteric interaction between the enzymes and ADP. In accordance with the enzymes from non-mammalian sources, ${ }^{p, 102}$ no activation by ADP was observed in the enzymes from both species when NADPH was used as coenzyme. The effects of ATP, AMP and leucine on the liver enzymes from both species were similar to the corresponding effects on the muscle enzymes. The activation curves of these activators were hyperbolic for the enzymes from both species.

Once the enzymes from both species were fully activated by ADP, they were not further stimulated by the addition of other activators, whereas the enzymes partially activated by ATP, AMP, leucine and inorganic salts were further activated to a maximum activity by the addition of ADP. The enzymes of both tissues either from $P$. cantonensis

Table 2. Effects of activators, inhibitors and their interaction with ADP (relative activities)

\begin{tabular}{|c|c|c|c|c|c|c|c|c|}
\hline & \multicolumn{4}{|c|}{ P. cantonensis } & \multicolumn{4}{|c|}{ T. obscurus obscurus } \\
\hline & \multicolumn{2}{|c|}{ Liver } & \multicolumn{2}{|c|}{ Muscle } & \multicolumn{2}{|c|}{ Liver } & \multicolumn{2}{|c|}{ Muscle } \\
\hline & $-\mathrm{ADP}$ & $+\mathrm{ADP}$ & $-\mathbf{A D P}$ & $+\mathrm{ADP}$ & $-\mathrm{ADP}$ & $+\mathrm{ADP}$ & $-\mathrm{ADP}$ & $+\mathrm{ADP}$ \\
\hline No addition & $100 \%$ & $600 \%$ & $100 \%$ & $350 \%$ & $100 \%$ & $380 \%$ & $100 \%$ & $320 \%$ \\
\hline \multicolumn{9}{|l|}{ Activator } \\
\hline ATP $(1.5 \mathrm{mM})$ & 156 & 542 & 154 & 336 & 174 & 370 & 150 & 315 \\
\hline $\operatorname{AMP}(1.0 \mathrm{~mm})$ & 192 & 563 & 189 & 326 & 174 & 374 & 164 & 305 \\
\hline Leucine ( $5 \mathrm{~mm}$ ) & 239 & 537 & 249 & 354 & 271 & 360 & 224 & 300 \\
\hline $\mathrm{MgCl}_{2}(100 \mathrm{~mm})$ & 187 & - & 192 & - & 174 & - & 185 & - \\
\hline $\mathrm{NaCl}(200 \mathrm{~mm})$ & 138 & 600 & 146 & 350 & - & - & - & - \\
\hline $\mathrm{KCl}(100 \mathrm{~mm})$ & 132 & - & 145 & - & - & - & - & - \\
\hline $\mathrm{MgSO}_{4}(50 \mathrm{mM})$ & 117 & - & 113 & - & - & - & - & - \\
\hline $\mathrm{Na}_{2} \mathrm{SO}_{4}(50 \mathrm{~mm})$ & 129 & - & 143 & - & - & - & - & - \\
\hline \multicolumn{9}{|l|}{ Inhibitor } \\
\hline GTP $(0.01 \mathrm{mM})$ & 19 & 468 & 19 & 263 & 13 & 127 & 16 & 85 \\
\hline $\mathrm{NAD}^{+}(2 \mathrm{mM})$ & 39 & 295 & 31 & 134 & 49 & 243 & 44 & 150 \\
\hline \multicolumn{9}{|l|}{ Glutamate } \\
\hline$(32 \mathrm{~mm})$ & 53 & 338 & 50 & 190 & 50 & 240 & 55 & 138 \\
\hline Succinate ( $5 \mathrm{~mm}$ ) & 70 & 472 & 84 & 302 & 63 & 254 & 79 & 243 \\
\hline
\end{tabular}

Enzymes were assayed in the direction of reductive amination under the optimal conditions. When added, ADP concentration was $0.15 \mathrm{mM}$.

Table 3. Apparent $K a$ and $K i$ values of glutamate dehydrogenase from liver and muscle of $P$. cantonensis and of T. obscurus obscurus

\begin{tabular}{|c|c|c|c|c|}
\hline \multirow{2}{*}{ Kinetic constants, $\mathrm{mM}$} & \multicolumn{2}{|c|}{ P. cantonensis } & \multicolumn{2}{|c|}{ T. obscurus obscurus } \\
\hline & Liver & Muscle & Liver & Muscle \\
\hline$K a \mathrm{ADP}$ & $0.023 \pm 0.002(16)$ & $0.031 \pm 0.002(16)$ & $0.024 \pm 0.001(3)$ & $0.026 \pm 0.002(3)$ \\
\hline$K a$ Leucine (-ADP) & $0.098 \pm 0.010(3)$ & $0.116 \pm 0.010(3)$ & $0.098 \pm 0.012(3)$ & $0.087 \pm 0.016(3)$ \\
\hline$K i$ GTP $(-\mathrm{ADP})$ & $0.0013 \pm 0.0001(7)$ & $0.0013 \pm 0.0001(7)$ & $0.0012 \pm 0.0001(3)$ & $0.0013 \pm 0.0001$ \\
\hline$K i$ GTP $(+A D P)$ & $0.0201 \pm 0.0017(8)$ & $0.0245 \pm 0.0020(8)$ & $0.0030 \pm 0.0004$ & $0.0050 \pm 0.007(3)$ \\
\hline$K i \mathrm{NAD}^{+}(+\mathrm{ADP})$ & $0.87 \pm 0.18$ & $0.79 \pm 0.24(3)$ & $0.65 \pm 0.04(3)$ & $0.69 \pm 0.13(3)$ \\
\hline$K i$ Glutamate $(+\mathrm{ADP})$ & $15.16 \pm 1.72(5)$ & $11.33 \pm 1.45(5)$ & $14.52 \pm 0.80(3)$ & $17.29 \pm 1.63(3)$ \\
\hline
\end{tabular}


or from $T$. obscurus obscurus had essentially similar $K a$ values for ADP (Table 3). No difference was also found among the apparent $K a$ values for leucine.

Of several inorganic salts examined, $\mathrm{MgCl}_{2}$ was the most effective in activating the enzymes from $P$. cantonensis and $\mathrm{MgSO}_{4}$ was the lowest. On the other hand, the effect of $\mathrm{Na}_{2} \mathrm{SO}_{4}$ on the enzymes was similar to that of $\mathrm{NaCl}$ as well as $\mathrm{KCl}$. The effect of $\mathrm{MgCl}_{2}$ on the enzymes from $T$. obscurus obscurus was similar to that of the enzymes from $\boldsymbol{P}$. cantonensis.

In the direction of reductive amination, the enzymes from both species were inhibited by the reaction products, $\mathrm{NAD}^{+}$and glutamate. Not any species-difference was found in the effects of $\mathrm{NAD}^{+}$or of glutamate on the enzymes examined. Similarly, no difference was observed in the effects of succinate on the enzymes from the two gobid fishes. The greatest degree of inhibition was obtained with GTP, and GTP at a concentration of $0.01 \mathrm{~mm}$ reduced the activities of the enzymes from both species to less than $20 \%$ of the activities in the absence of GTP. The subsequent addition of ADP (0.15 mM) to GTPinhibited enzymes restored the activities. This effect of ADP was more pronounced for the enzymes of both tissues from $P$. cantonensis than that for the enzymes from $T$. obscurus obscurus; ADP restored about $80 \%$ of the activities in the absence of GTP for the enzymes from $P$. cantonensis as compared with $30 \%$ for the enzymes from $T$. obscurus obscurus. On the other hand, for the succinate-inhibited enzymes, a degree of releasing the inhibition by ADP was not different among the enzymes examined $(70-90 \%$ of the activities was restored). For the liver and muscle enzymes from both species inhibited by reaction products, ADP was less effective in releasing the inhibition, restoring $40-60 \%$ of the activities.

A clear species-difference was not observed in either the apparent $K i$ values for $\mathrm{NAD}^{+}$or the $K i$ 's for glutamate of the enzymes examined. No difference was also observed among the $K i$ 's for GTP in the absence of ADP (Table 3). On the other hand, in the presence of ADP, the apparent $K i$ values for GTP of the enzymes from $P$. cantonensis were much higher than those observed with the enzymes from $T$. obscurus obscurus; ADP increased the $K i$ values of the enzymes from $P$. cantonensis 15 - to 20 -fold compared with 3 - to 4-fold of the enzymes from $T$. obscurus obscurus.

\section{Discussion}

The liver and muscle enzymes from the two gobid fishes resemble the enzymes from other non-mammalian sources in several aspects including the apparent $\mathrm{Km}$ for substrate $\left(\mathrm{NH}_{4}^{+}\right.$, $\alpha$-keotglutarate and NADH), activation by ADP, AMP and leucine, inhibition by GTP, succinate and reaction products $\left(\mathrm{NAD}^{+}\right.$and glutamate) and a lower specificity for NADPH as coenzyme. $^{6-11}$ It should be noted that the enzymes from $P$. cantonensis, especially the liver enzyme, were more strongly affected by ADP-GTP interaction than those from $T$. obscurus obscurus as well as the enzyme from the eel liver. ${ }^{10}$ This fact suggests that the enzymes from $P$. cantonensis are more tightly regulated by the energy status of the cell. A similar difference is also observed between glutamate dehydrogenase from kidneys of air- and water-breathing osteoglossiform fishes. ${ }^{8)}$

Although little information is available about the properties of the muscle enzyme from other fish sources, the catalytic properties of the muscle enzyme from $P$. cantonensis were different from those of the muscle enzyme from $T$. obscurus obscurus as well as the liver enzymes from both species. In particular, it is interesting to note that of the tissues from both species examined, the muscle enzyme from $P$. cantonensis had the lowest $\mathrm{Km}$ value for $\mathrm{NH}_{4}^{+}$. In general, the $\mathrm{Km}$ of glutamate dehydrogenase for $\mathrm{NH}_{4}^{+}$is high as compared with the concentration in vivo, and the glutamate dehydrogenase from fish sources is considered to play an important role for the oxidative deamination rather than the reductive amination under normal circumstances. ${ }^{12-14}$ ) However, in the case of $P$. cantonensis kept out of water, the ammonia level in the muscle increased up to about $20 \mathrm{mM} / \mathrm{kg}$ tissue water, and in accordance with this, free amino acids, especially non-essential ones increased greatly. ${ }^{3)}$ In addition, Tamura et $a l^{15}{ }^{15}$ reported that oxygen consumption of $P$. cantonensis kept out of water decreased about $60 \%$ of that kept in a diluted sea water. This finding implies that the tissue, especially the muscle of $\boldsymbol{P}$. cantonensis is exposed to a hypoxic condition during the period out of water. Any increase in NADH and ADP as a result of hypoxic stress would strongly activate the reductive amination of $\alpha$-keotglutarate. Thus, the glutamate dehydrogenase from the muscle of $P$. cantonensis seems to play an important role in 
removing ammonia from the tissue by means of reductive amination of $\alpha$-ketoglutarate, otherwise ammonia may reach a toxic level. Since the activities of the liver enzyme from $P$. cantonensis increased greatly when the fish was placed in conditions of water-shortage, the liver enzyme would also play an important role for the regulation of amino acid pool in the whole body, functioning either direction of amination or deamination depending on a physilogical state of the fish.

It has been known that in $T$. obscurus obscurus (unpublished) as well as several euryhaline teleosts adapted to a hyper-osmotic medium, free amino acids were accumulated greatly in their muscle tissues, which play an important role in cell volume regulation. ${ }^{10-18}$ ) Therefore, the function of the muscle enzyme catalyzing the reductive amination as in $P$. cantonensis appears to be rather general in euryhaline teleosts. However, a lower $\mathrm{Km}$ value for $\mathrm{NH}_{4}^{+}$of the muscle enzyme from $P$. cantonensis together with a strong ADPGTP interaction appears to be well suited for amphibious mode of life. Thus, in conclusion, the glutamate dehydrogenase of $\boldsymbol{P}$. cantonensis, especially the muscle enzyme appears to have been modified to perform a primarily reductive amination in keeping with a need of detoxication of ammonia as well as of cell volume regulation during its terrestrial life.

\section{References}

1) M.S. Gordon, I. Boetius, D. H. Evans, R. MCCARTHY, and L. C. Oglessy: J, exp. Biol., 50, 141-149 (1969).

2) H. Morit, K. Nishikata and O. Tamura: Comp.
Biochem. Physiol., 60A, 189-193 (1978).

3) K. Iwata, I. Kakuta, M. Ikeda, S. Kimoto, and N. WADA: Comp. Biochem. Physiol., 68A, 589596 (1980).

4) P. A. Janssens: Comp. Biochem. Physiol, 11, 105-117 (1964).

5) J. B. BALINSKY: in "Comparative Biochemistry of Nitrogen Metabolism" (ed. by J. W. CAMPBELL) Vol. 2, Academic Press, London, New York, 1970, pp. 519-637.

6) L. Corman, L. M. Prescott and N. O. Kaplan: J. Biol. Chem., 242, 1383-1390 (1967).

7) E. L. Smith, B. M. Austen, K. M. Blumenthal, and J. Nyc: in "The enzymes" (ed. by $P$. BoYer), Vol. 11, Academic Press, New York, 1957, pp. 293-368.

8) K. B. Storey, H. E. Guderley, M. Guppy, and P. W. HochachKa：Can. J. Zool., 56, 845-851 (1978).

9) J. H. A. Field, W. R. DRIedzic, C. J. French, and P.W. HochaChKa: Can. J. Zool., 56, 809-813 (1978).

10) S. Hayashi, K. Ise, T. Itakura, and Z. Ooshiro: Bull. Japan Soc. Sci. Fish., 48, 697-701 (1982).

11) B. O. Wiggert and P. P. Cohen: J. Biol. Chem., 241, 210-216 (1966).

12) R. L. MCBeAN, M. J. NePpel and L. Goldstein: Comp. Biochem. Physiol., 18, 909-920 (1966).

13) M. J. Walton and C. B. CoweY: Comp. Biochem. Physiol, 57B, 143-149 (1977).

14) A. V. WaArde: Comp. Biochem. Physiol., 68B, 407-413 (1981).

15) O. TAMura, H. Morit, and M. Yuzuriha: $J$. exp. Biol., 65, 97-107 (1976).

16) A. K. Huggins, and L. Colley: Comp. Biochem. Physiol., 38B, 537-541 (1971).

17) L. Colley, F. R. Fox, and A. K. Huggins: Comp. Biochem. Physiol, 48A, 757-763 (1974).

18) P. LASSERre and R. Gilles: Experientia, 27, 1434-1435 (1971). 